\title{
In silico study of lutein as anti-HER-2 receptors in breast cancer treatment
}

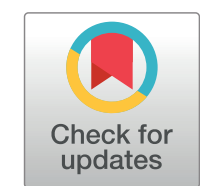

\author{
Ni Ketut Nitya Cahyani $\mathbb{D}$, Wahyu Nadi Eka Putri $\mathbb{B}$, I Kadek Diva Dwivayana $\mathbb{D}$,

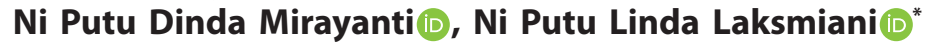

Departement of Pharmacy, Faculty of Mathematics and Natural Science, Udayana University, Bukit Jimbaran, Badung, Bali 80361, Indonesia

${ }^{*}$ Corresponding author: Departement of Pharmacy, Faculty of Mathematics and Natural Science, Udayana University, Bukit Jimbaran, Badung, Bali 80361, Indonesia. Email: laksmini@unud.ac.id

\begin{abstract}
Human Epidermal Receptor-2 (HER-2) overexpression is implicated in breast cancer progression; thus, HER-2 is widely used as the target of anticancer therapy. Lapatinib is a drug widely used to inhibit the HER-2 receptor and tyrosine kinase; however, it develops drug resistance. Lutein is promising to be developed as breast cancer therapy. This study aims to determine the mechanism of inhibition of HER-2 receptor overexpression by lutein in silico. Molecular docking was carried out by optimizing the lutein and lapatinib, preparing of protein target HER-2 (PDB ID 3PP0), validating of molecular docking protocol, and docking of lutein and lapatinib on HER-2. The study resulted in the binding energy of $-12.37 \mathrm{kcal} / \mathrm{mol}$, while the binding energy of the native ligand and lapatinib to HER-2 was $-10.43 \mathrm{kcal} / \mathrm{mol}$ and $-12.25 \mathrm{kcal} / \mathrm{mol}$, respectively. The binding energy showed that lutein has potential as breast anticancer suggested from the stronger affinity to HER2.
\end{abstract}

Keywords: breast cancer, HER-2, lutein, lapatinib, molecular docking, in silico

\section{Introduction}

Breast cancer is the fifth leading cause of cancer death worldwide, with 685,000 deaths [1]. Fifty percent of breast cancer cases are caused by estrogen receptor overexpression, and $30 \%$ of them are caused by overexpression of Human Epidermal Receptor-2 (HER2). Cancer cell invasion may occur due to overexpression of HER-2 receptors. The overexpression of HER-2 leads to increased proliferation, metastasis, as well as induces angiogenesis and anti-apoptosis [2]. HER-2 overexpression can induce spontaneous dimerization and autophosphorylation, thereby triggering the activation of focal adhesion kinase (FAK) involved in the migration and metastasis of cancer cells [3].

Breast cancer is mainly treated with chemotherapy or surgery, which are also used in combination. On the other side, various chemical drugs are used in chemotherapy to destroy the cancer cell tissue, but these chemotherapeutic agents cannot distinguish normal cells from cancer cells. This condition will cause several side effects such as vomiting, diarrhea, and alopecia [4]. Breast cancer therapy methods need to be developed to have specific targets and high selectivity against breast cancer. The therapy used in the treatment of HER-2 positive breast cancer is lapatinib. The mechanism of action of lapatinib as an oral dual tyrosine kinase inhibitor is to target the epidermal growth factor receptor (EGFR) and human epidermal growth factor receptor-2 (HER-2) [5].

One strategy to overcome that problem is by exploring the potential of natural ingredients to be developed into pharmaceutical products. Lutein is one of the important xanthophyll present in many leafy vegetables and certain fruits. Lutein also has been proven to help combat several lifestyle complications, including cancer $[6,7]$. This lutein needs to be given special and intensive attention because of its benefits for health, one of which has anticarcinogenic activity [8]. Lutein has a very active anticancer activity against MCF-7 breast cancer cells with an $\mathrm{IC}_{50}$ value of 3.10 $\mathrm{g} / \mathrm{mL}[9]$.

The mechanism of lutein to inhibit some human breast cancer cells has been explained. The growth inhibitory effect of lutein in MCF-7 and MDA-MB-231 breast cancer cells are facilitated by a disrupted balance between intracellular ROS and antioxidant defense system $[10,11]$. The growth inhibitory effect of lutein in MCF-7 and MDA-MB-231 breast cancer cells are linked with repressed redox response and survival signaling. This indication speculated that 
a

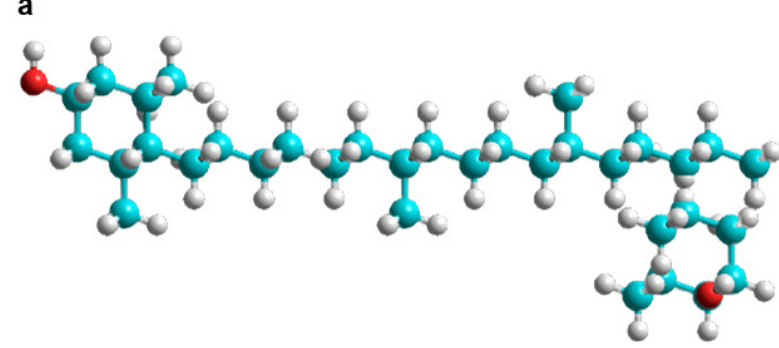

c

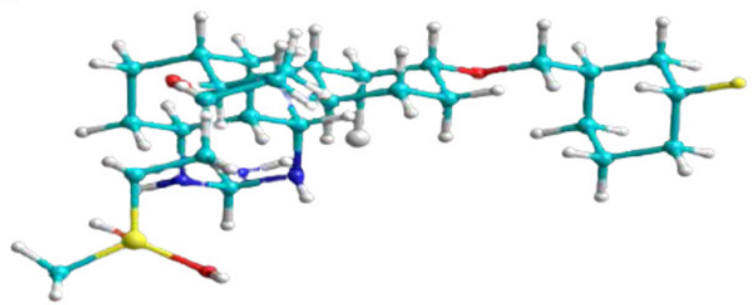

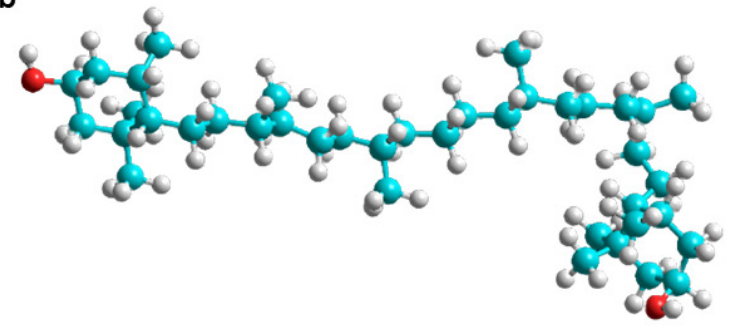

d

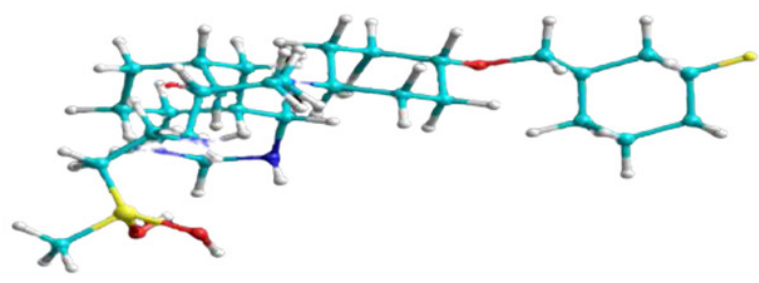

Figure 1. Optimized three-dimensional lutein and lapatinib structure. (a) Single point calculation of lutein, (b) geometry optimization of lutein, (c) single point calculation of lapatinib, (d) geometry optimization of lapatinib

lutein's attenuation of survival signals might force the breast cancer cells to undergo apoptosis [12].

However, the mechanism by which lutein inhibits the HER-2 receptor, a protein that plays a role in the growth and differentiation process of normal epithelial cells, is yet unknown [13]. Therefore, an in silico molecular docking can be utilized to examine the inhibition of HER-2 by lutein.

\section{Methods}

\section{Optimization of the structure of lutein and lapatinib}

Three-dimensional structure of lutein and lapatinib downloaded from https://pubchem.ncbi.nlm.nih.gov/. The three-dimensional structure of the lutein and lapatinib was optimized using the Hyperchem 8 program. Optimization was carried out using the AM1 (Austin Model 1) semi-empirical computational method, then single-point calculation and geometry optimization were performed.

\section{Preparation of HER-2 protein}

The HER-2 protein used in this study was downloaded from http://www.rcsb.org (PDB ID: $3 \mathrm{PP} 0)$ containing native ligand (2-\{2-[4-(\{5-chloro6-[3-(trifluoromethyl) phenoxy]pyridine-3-yl\}amino)5H-pyrrolo[3,2d]pyrimidin-5-yl]ethoxy\}ethanol) (03Q). The HER-2 protein was prepared using the Chimera 1.10.1 program to separate the protein from its native ligand.

\section{Molecular docking validation}

Molecular docking was validated by using Autodock 4.2. Grid box arrangement was also carried out by adjusting the coordinate size of the grid center and grid size, with the grid box size $x=80, y=50, z=50$ and the grid center $\mathrm{x}=1.259, \mathrm{y}=0.303, \mathrm{z}=0.565 .03 \mathrm{Q}$ was redocked on the HER-2 protein, and the protocol was valid by the value of Root Mean Square Distance $(\mathrm{RMSD}) \leq 3.0 \AA$ [14].

\section{Docking lutein and lapatinib}

The optimized lutein and lapatinib were then docked to the prepared HER-2 protein using Autodock 4.2 with a similar grid box size as the validation step. The docking study evaluated lutein or lapatinib's binding energy and interaction to HER-2 protein [15]. A lower binding energy value implies a stronger and more stable bond. The interaction was evaluated by analyzing the type of bonds such as hydrogen, Van der Waals, hydrophobic, and electrostatic [16].

\section{Results}

The lutein and lapatinib structures were optimized and resulted in single-point energy of -9541.96 and $-8781.79 \mathrm{kcal} / \mathrm{mol}$, and geometric energy of -11309.61 $\mathrm{kcal} / \mathrm{mol}$ and $-8860.12 \mathrm{kcal} / \mathrm{mol}$, respectively. HER-2 protein was prepared by separating 03Q native ligand from protein. Chain A consisted of native ligand 03Q was selected for this study. The validation process produced 


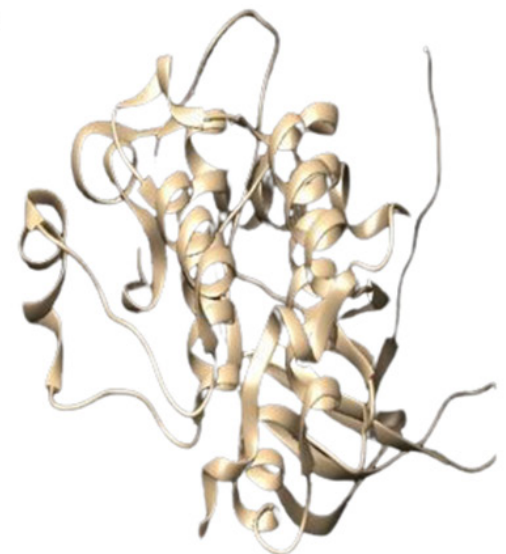

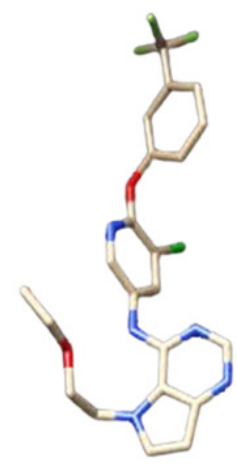

Figure 2. Preparation of three-dimensional structure of HER-2 protein. (a) structure of HER-2 protein without native ligand, (b) native ligand $03 \mathrm{Q}$ structure

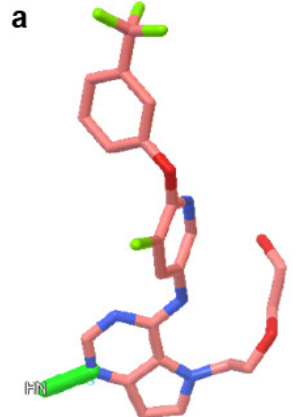

MET801 b

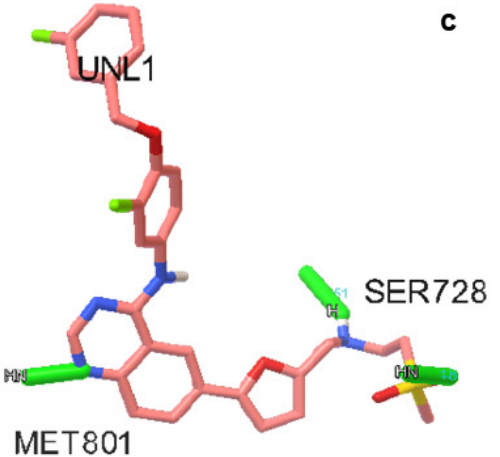

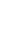

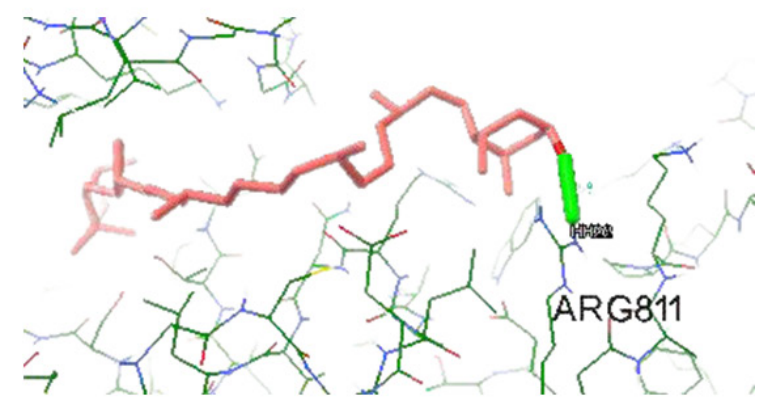

Figure 3. Interaction of native ligand, lapatinib, and lutein to HER-2. (a) native ligand 03Q, (b) lapatinib, (c) lutein

10 conformational $03 \mathrm{Q}$ native ligands towards HER-2 binding sites with different RMSD values and binding energies. The selected conformation had an RMSD of $0.73 \AA$ value and met the validation criteria (RMSD $\leq 3 \AA$ ) [15]. The binding energy of 03Q native ligand to HER-2 was $-10.43 \mathrm{kcal} / \mathrm{mol}$ (Table 1 ). The docking results showed that there were 10 conformations between lapatinib and HER-2 protein, as well as lutein and HER-2 protein. The binding energy of lapatinib was $-12.25 \mathrm{kcal} / \mathrm{mol}$ (Table 2), while binding energy of lutein was $-12.37 \mathrm{kcal} / \mathrm{mol}$ (Table 3 ).

The visualization analysis indicated that lapatinib and native ligand (03Q) interacted with methionine (MET 801) residue through hydrogen bonding interaction. This result suggests that lapatinib is able to occupy the active site of HER-2 protein as the original position of $03 \mathrm{Q}$ native ligand. The visualization analysis indicated that lutein interacted with arginine (ARG 811) residue through hydrogen bonding interaction. Other bonds that can form such as Van der Waals (vdw), hydrophobic (desolv), and electrostatic (elec) bonds.
Table 1. Validation of molecular docking

\begin{tabular}{|c|c|c|c|}
\hline Protein & Ligand & RMSD (Å) & $\begin{array}{l}\text { Bond energy } \\
\text { (kcal/mol) }\end{array}$ \\
\hline \multirow{10}{*}{ HER-2 } & \multirow{10}{*}{$03 \mathrm{Q}$} & 1.60 & -10.01 \\
\hline & & 0.73 & -10.43 \\
\hline & & 2.67 & -9.08 \\
\hline & & 2.28 & -7.10 \\
\hline & & 1.70 & -10.06 \\
\hline & & 2.67 & -10.26 \\
\hline & & 2.54 & -8.42 \\
\hline & & 1.84 & -10.43 \\
\hline & & 2.72 & -8.67 \\
\hline & & 2.85 & -7.66 \\
\hline
\end{tabular}

\section{Discussion}

Our results suggest that lutein shows the potential activity as an anticancer agent based on the lower binding affinity compared to lapatinib. The obtained binding energy of lutein was $-12.37 \mathrm{kcal} / \mathrm{mol}$ lower 
Table 2. Docking of lapatinib on HER-2 protein

\begin{tabular}{|c|c|c|c|c|}
\hline Protein Target & Ligand & $\begin{array}{c}\text { Van Der Waals, } \\
\text { Hydrophobic Energy } \\
\text { (kcal/mol) }\end{array}$ & $\begin{array}{l}\text { Electrostatic Energy } \\
\text { (kcal/mol) }\end{array}$ & $\begin{array}{l}\text { Bonds Energy } \\
\text { (kcal/mol) }\end{array}$ \\
\hline \multirow{10}{*}{ HER-2 } & \multirow{10}{*}{ Lapatinib } & -12.61 & -0.33 & -9.00 \\
\hline & & -7.54 & -0.22 & -4.04 \\
\hline & & -15.23 & -0.30 & -12.25 \\
\hline & & -10.31 & -0.33 & -6.69 \\
\hline & & -8.59 & -0.92 & -6.22 \\
\hline & & -11.44 & -0.56 & -8.72 \\
\hline & & -11.41 & 0.50 & -7.62 \\
\hline & & -15.02 & -0.28 & -11.73 \\
\hline & & -12.75 & -0.01 & -9.48 \\
\hline & & -13.05 & -1.02 & -10.79 \\
\hline
\end{tabular}

Table 3. Docking of lutein on HER-2 protein

\begin{tabular}{|c|c|c|c|c|}
\hline Protein Target & Ligand & $\begin{array}{c}\text { Van Der Waals, } \\
\text { Hydrophobic Energy } \\
\text { (kcal/mol) }\end{array}$ & $\begin{array}{l}\text { Electrostatic Energy } \\
(\mathrm{kcal} / \mathrm{mol})\end{array}$ & $\begin{array}{c}\text { Bonds Energy } \\
\text { (kcal/mol) }\end{array}$ \\
\hline \multirow{10}{*}{ HER-2 } & \multirow{10}{*}{ Lutein } & -14.66 & -0.02 & -11.97 \\
\hline & & -15.02 & -0.03 & -12.37 \\
\hline & & -14.40 & -0.02 & -11.71 \\
\hline & & -13.82 & -0.13 & -11.14 \\
\hline & & -8.63 & -0.04 & -5.99 \\
\hline & & -10.74 & -0.02 & -8.05 \\
\hline & & -12.97 & -0.01 & -10.29 \\
\hline & & -10.57 & -0.01 & -7.89 \\
\hline & & -10.90 & 0.01 & -3.59 \\
\hline & & -14.35 & -0.04 & -11.71 \\
\hline
\end{tabular}

than $03 \mathrm{Q}$ native ligand $(-10.43 \mathrm{kcal} / \mathrm{mol})$ and lapatinib $(-12.25 \mathrm{kcal} / \mathrm{mol})$.

Lutein (xanthophyll, beta-carotene-3,3'-diol) is one of the carotenoids that have been known for their anticarcinogenic activity and is useful for combating several cancers. Carotenoid-enriched fractions of Spondias mombin inhibited ATP kinase domain of HER-2. By using the similar methods and protein target (HER-2, PDB ID 3PP0) with grid coordinates $\mathrm{x}=17.1, \mathrm{y}=16.55, \mathrm{z}=26.6$ of $03 \mathrm{Q}$ native ligand, the binding energy of astaxanthin, 7,7',8,8'-tetrahydro- $\beta, \beta$ carotene, $\beta$-carotene-15,15'-epoxide, and lapatinib were of $-3.0,-8.5,-11.5$, and $-10.6 \mathrm{kcal} / \mathrm{mol}$, respectively [17]. Another study using bioactive compounds of Panax bipinnatifidus and $P$. pseudoginseng indicated that luteolin 7-O-glucoside showed the highest binding affinity towards receptor HER2 by using Schrödinger suite 2020-3 of Glide module with docking score and Glide g score (G-Score) of $-13.272 \mathrm{kcal} / \mathrm{mol}$ [18]. These two findings support that lutein as a carotenoid compound can inhibit HER-2.

In the present study, there are similarities in binding amino acid residues between 03Q native ligand and lapatinib. The hydrogen bonding interaction occurred 
via methionine (MET 801) residue (Figure 3a, b). This interaction similarity indicates that lapatinib occupied the same active site of the 03Q position. Binding amino acid residues between lutein and HER2 occurred via arginine (ARG 811) residue (Figure 3c). This interaction was difference due to differences in the $3 \mathrm{D}$ conformational structure of the native ligand with lutein for determine the most stable state in binding to the pocket binding site HER-2. We found that lutein interacted with HER-2 protein through Van der Waals (vdw), hydrophobic (desolv), and electrostatic (elec) bonds. Future in silico study by using molecular dynamics is needed to further clarify the potential of lutein as anti-breast cancer.

\section{Conclusion}

In summary, this study reveals lutein interacted with HER-2 protein and promising to be developed as an HER-2 inhibitor in cancer therapy.

\section{Acknowledgments}

None.

\section{Funding}

This work was supported by Direktorat Jenderal Pembelajaran dan Kemahasiswaan, Kementerian Riset, Teknologi, dan Pendidikan Tinggi Republik Indonesia through Program Kreativitas Mahasiswa 2021 (grant number 015/E2/PPK/SPPK/PKM/2021).

\section{Declaration of interest}

The authors declare no competing interests.

\section{Author contributions}

NKNC, NPDM, NPLL conceptualized the study design; IKDD and WNEP investigated the data; NKNC and WNEP wrote the original draft; NKNC, NPDM, IKDD reviewed and edited the final version; NKNC acquitted the funding; NPLL supervised all experiments. All authors read and approved the final manuscript.

Received: 25 September 2021

Accepted: 28 November 2021

Published online: 1 December 2021

\section{References}

1. Sung H, Ferlay J, Siegel RL, Laversanne M, Soerjomataram I, Jemal A, et al. Global cancer statistics 2020: GLOBOCAN estimates of incidence and mortality worldwide for 36 cancers in 185 countries. CA Cancer J Clin. 2021;71: 209-249. doi:10.3322/caac. 21660

2. Dai X, Xiang L, Li T, Bai Z. Cancer hallmarks, biomarkers and breast cancer molecular subtypes. J Cancer. 2016;7: 1281-1294. doi:10.7150/jca.13141

3. Gevorgyan A, Bregni G, Galli G, Zanardi E, de Braud F, Di Cosimo S. HER2-Positive Neuroendocrine Breast Cancer: Case Report and Review of Literature. Breast Care (Basel). 2016;11: 424-426. doi:10.1159/000453572

4. Li S, So T, Tang G, Tan H-Y, Wang N, Ng BFL, et al. Chinese Herbal Medicine for Reducing ChemotherapyAssociated Side-Effects in Breast Cancer Patients: A Systematic Review and Meta-Analysis. Front Oncol. 2020;10. doi:10.3389/fonc.2020.599073

5. D’Amato V, Raimondo L, Formisano L, Giuliano M, De Placido S, Rosa R, et al. Mechanisms of lapatinib resistance in HER2-driven breast cancer. Cancer Treat Rev. 2015;41: 877-883. doi:10.1016/j.ctrv.2015.08.001

6. Nidhi B, Sharavana G, Ramaprasad TR, Vallikannan B. Lutein derived fragments exhibit higher antioxidant and anti-inflammatory properties than lutein in lipopolysaccharide induced inflammation in rats. Food Funct. 2015;6: 450-460. doi:10.1039/c4fo00606b

7. Gansukh E, Mya KK, Jung M, Keum Y-S, Kim DH, Saini RK. Lutein derived from marigold (Tagetes erecta) petals triggers ROS generation and activates Bax and caspase- 3 mediated apoptosis of human cervical carcinoma (HeLa) cells. Food Chem Toxicol. 2019;127: 11-18. doi:10.1016/j.fct.2019.02.037

8. Sowbhagya HB, Sushma SB, Rastogi NK, Naidu MM. Effect of pretreatments on extraction of pigment from marigold flower. J Food Sci Technol. 2013;50: 122-128. doi:10.1007/s13197-011-0313-4

9. Omar WM, Ahmed AE, Raslan M, El-Nesr K, Ali MM, De Abdelmaksoud $M$, et al. Effect of Lutein-Rich Extract on Human Cancer Cells. Middle East Journal of Cancer. 2021;

10. Kavalappa YP, Gopal SS, Ponesakki G. Lutein inhibits breast cancer cell growth by suppressing antioxidant and cell survival signals and induces apoptosis. J Cell Physiol. 2021;236: 1798-1809. doi:10.1002/jcp.29961

11. Basak P, Sadhukhan P, Sarkar P, Sil PC. Perspectives of the Nrf-2 signaling pathway in cancer progression and therapy. Toxicol Rep. 2017;4: 306-318. doi:10.1016/j. toxrep.2017.06.002

12. Mitsuishi Y, Motohashi H, Yamamoto M. The Keap1-Nrf2 system in cancers: stress response and anabolic metabolism. Front Oncol. 2012;2: 200. doi:10.3389/fonc.2012.00200

13. Gong X, Smith JR, Swanson HM, Rubin LP. Carotenoid Lutein Selectively Inhibits Breast Cancer Cell Growth and Potentiates the Effect of Chemotherapeutic Agents through ROS-Mediated Mechanisms. Molecules. 2018;23. doi:10.3390/molecules23040905 
14. Jain AN, Nicholls A. Recommendations for evaluation of computational methods. J Comput Aided Mol Des. 2008;22: 133-139. doi:10.1007/s10822-008-9196-5

15. Kitchen DB, Decornez H, Furr JR, Bajorath J. Docking and scoring in virtual screening for drug discovery: methods and applications. Nat Rev Drug Discov. 2004;3: 935-949. doi:10.1038/nrd1549

16. Du X, Li Y, Xia Y-L, Ai S-M, Liang J, Sang P, et al. Insights into Protein-Ligand Interactions: Mechanisms, Models, and Methods. Int J Mol Sci. 2016;17. doi:10.3390/ijms17020144
17. Metibemu DS, Akinloye OA, Omotuyi IO, Okoye JO, Popoola MA, Akamo AJ. Carotenoid-Enriched Fractions From Spondias mombin Demonstrate HER2 ATP Kinase Domain Inhibition: Computational and In Vivo Animal Model of Breast Carcinoma Studies. Front Oncol. 2021;11: 687190. doi:10.3389/fonc. 2021.687190

18. Paul D, Mahanta S, Tag H, Das SK, Das Gupta D, Tanti $\mathrm{B}$, et al. Identification of tyrosine kinase inhibitors from Panax bipinnatifidus and Panax pseudoginseng for RTKHER2 and VEGFR2 receptors, by in silico approach. Mol Divers. 2021; doi:10.1007/s11030-021-10304-5 